\title{
On Chinese Folk Dance Teaching Innovation
}

\author{
Yan Xu \\ College of Music and Performing Arts, Yibin University, Yibin, 644000, China
}

\begin{abstract}
Keywords: Folk dance. Teaching. Class. Innovation
\end{abstract}
\begin{abstract}
The folk dance is originated in the body language in people`s daily life, the dance is performed by the abstraction of the daily activity, it can also be called Hula or country dance. What is different from the ballet or sport dancing is the folk dance match the special music,customs. The performance form can be very various, the dance style is diversified,visualize and vivid. This paper talks about the Chinese folk dance teaching innovation from five respects which are mastering the folk dance moves characters, introducing diversified dancing teaching methods, implementing personalized teaching methods, designing all kinds of folk scenes, realizing three-dimensional development.of the teaching evaluation system.
\end{abstract}

\section{Introduction}

The Chinese folk dance is originated in and developed in the civil society, it is the most authentic reflect of the folk culture of different ethnic group. Meanwhile, the folk dance will be influenced by the local folk custom just like other culture forms. Such as the life style,religion belief and custom culture etc. At the very beginning, the folk dance is a dance form created by people for entertainment, there is no fixed moves. Due to the continuous development of the higher education, many higher learning institution all have opened folk dancing course. While the level of the students are uneven, and different students `understanding of the folk dance is also different, so it makes the current folk dance teaching become a formalism,most of the class teaching is simply the stiff imitation of some simple dance moves and skills, few teacher would lead the students to comprehend the essence of the folk dance and the strong nationalistic fury. The nature of different folk dance is the true reflect of the local culture, this require the teachers of higher institutions` folk dancing teachers to break the old education think strategy, conduct teaching innovation instead of teaching dance moves and gists, study the essence of the folk dance deeply, and let the students truly master the core sprit of folk dance.

\section{The posture character of folk dance.}

As for the performance of Chinese folk dance, the most important point is controlling the posture, because the posture is the center of all the moves. Whether the folk dancer`s movement is perfect or not is decided by the correctness of posture. Meanwhile, the posture will also decide the movement rhythm and style. Firmly grasp all the folk dancing`s character, and earnestly take control of the posture rhythm, this is the important foundation for an outstanding folk dancer. For example, Northeast yangko dance is a dancing form which is very popular in northeast China, people usually will generalize its character as forceful while stable, which means it contains beauty and force. It mainly use walking, stable and drum plus all kinds of towel flower`s changes to perform its character.For another example, a prominent character of the folk dance of Uighur ethnic group is the dancer`s back is very uptight and straight, the changes of the dance movement is various, high styling sense, the dance is humorous and funny, it is also very graceful and stable, the movement is elegant and expressive, easy and simple, makes people want to join in the dance floor.In the rhythm, the dancers are required to be straight but not stiff, quivered slightly but not trembling, able to get the upper part of the body open up, the steps is not discrete, body shaking and head moving, there are many spins as for the skills, there are many dot in the rhythm. Another example, there are many different forms Tibetan folk dance, its major character is bold and rough, tender and outgoing; the feature of Duixie is delicate and exquisite, liberal and expressive. 
There are close tie between the music and dancing, in most cases, the music and dancing are intermingled. The Tibetan folk dance usually will using the sleeves to express the deep feeling inside the dancers, regular flexion and fibrillation of the knees is the major feature of the Tibetan folk dance. Because the Tibetan people live in the plateau, its special geographic environment and life style distinguish them from other ethic group, they usually get used to loose their upper part, and slightly forward, thus to coordinate with the changing lower limb movement, and then the special dancing character is formed. Among all the Tibetan folk dancing forms, the continuous s slight fast and flexible flexion and uninterrupted pliable fibrillation is their common feature. Weather it is flexion or the fibrillation, the knees should be not only flexible, but also relaxed. While the upper part of body should be active at all. From this, we can draw a conclusion that it is very important to have good posture for a good folk dancer.

\section{The introduction of multi-dimensional dancing teaching methods}

For the teaching methods of folk dance in higher institutions, it has its own specialty, but it can not be separate from the modernized education`s requirement for high-quality talent. The first is using combined teaching approach, this means to make comparisons about the different moves, steps and style of all the different folk dance types, thus to build a organic entity. The second is emotional teaching method. Folk dance is rooted in the rich ethical culture and emotions. The advantage of college students is that they have already learned the knowledge of the life style ,custom and culture characters of all the ethnic groups, so the folk dance teaching in higher institutions must be good at discovering the key point from the dancing culture. The third is improvisation methods. In the higher institution`s folk dance teaching, in order to let the students become the main body, every students are dancing performer regardless of their foundation and background, each students can perform according to their own phycological changes.

\section{Conduct personalized character teaching methods}

In the development process of modern art, the personalized expression of the culture content has always been the brightest charm of the art. The art aesthetic of the Chinese folk dance is not only conductive to its own culture transmission rules, it is also set up a distinctive banner for its special dance culture character,moves and figures. The folk dance of the minority ethic groups has shown its colorful side. Facing such a enormous development space of folk dance, the teaching innovation of the folk dance course in the higher institutions should adhere to the principal of representative and typical, fully extract the moves of all kinds of folk dance, then develop this elements above into a special dancing language. In 1980s, the dancing education experts have put forward the elements teaching methods, which made a significant contribution for the folk dance teaching. While as people`s understanding of the folk dance goes deeper, also in order to break the model and standard of the old moves tradition, the folk dancing teaching system in higher institutions needs to further expand its vision, focus on the richer folk dance forms once again, hope to based on the continuous absorption and organization of the brand-new dance teaching material, inject new vigor to the folk dance teaching in higher institutions. Under such background, the higher institution`s folk dance teaching not only need to deeply implement the cultural content of the folk dance as its pillar, but also focus on the personalized class teaching system development, thus to reveal its regional characters, nationality and distinctive personality.

Because the folk dance resource of different national regions are different, some minority ethnic group `s folk dance is also various in its forms and types. Due to this reason, the folk dance course in Chinese higher institution firstly need to conduct macro study to the local culture art, and then dig reasonable national folk dance material selectively, as an important content of the class teaching. It is needed to keep its original form, and let the students better experience the essence of the folk dance in the process of learning, and feel the various style of the folk dance. This teaching is completely different from the training in the traditional folk dance teaching, instead it pays great attention to the 
understanding of personality and emotion, even the culture gene. Such as, there are dancing material of more than 25 minority ethnic groups, however, not all the minority groups can completely extract the folk dancing material which is fit for the teaching rules and elements. In order to better promote the folk dance in Yunnan, and more effectively preserve, inherit and develop the outstanding folk dance culture resource, the s dancing school of Yunnan higher institutions have achieve research fruits by going into different ethnic group to receive first-hand investigation and collection work, and integrate the research work of "Yunnan Representative folk dance" into dance teaching in the higher institution, thus to innovate the dance class teaching.

\section{The Design of Different Kinds of Folk Culture Scenes}

The folk dance is a art work created by the working people in their long-time working process, it is a natural dance moves. However, because the college students are lack of life experience, it is very difficult for college students to infiltrate this moves into stage performance, so this actually need the teachers to create correspondent dancing teaching scenes. Thus to help the college students to better devoted into the folk dance learning. The first is the design of stage scenes, the college students could turn to the stage, lighting and sound box to create a strong artistic effect, thus to better reflect the working scene and let the college students better participate into it. Such as, in the Uygur folk dancing teaching process, the teacher could guide the girl students to wear Uighur traditional dress and doppa, comb several small plait, by doing this, the charm of Uighur girls can be reflected. This simulation performance can make students feel personally on the scene, and it will be easier to accept. The second is the design of life scene, thus to make the students devote into the dance learning more quickly. Such as, in the rehearsal process of Northeast yangko dance, the teacher can display the harvest scene by modern mulit-media technology, and put something like corn and sorghum on the stage, and let the students better get into the mood. The third is the design of imaginary scenes. If it is difficult to find suitable material in the life, then other assistant teaching approach can be used, and let the students begin to associate. For example, when the teacher is talking about the Monogolian dance, it is very hard to display Monogolian people`s life panoramically, so the teachers can use the projector to paly some video or picture which can show the Monogolian customs. In the boundless grassland, scattered bits and pieces Monogolian Yurts, the Monogolian young man who are talented in riding and shooting sweep through the grassland freely. Start the teaching work by using the content above, the students could have some basic understanding of the lifestyle and customs of Monogolian people, then it would be much easier for the teachers to guide the students in their learning process.

\section{The realization of teaching evaluation system development in an all-dimensional way.}

The construction and development of the teaching evaluation system has always been an important links in the higher institutions teaching activity, it serve as an test for the learning achievement and promote the learner`s passion. One it is needed to build a all-dimensional evaluation system. Such as , the cross-grade evaluation between the students, which includes the evaluation to dancing major students and normal students. By doing this, it can erose the students ` passion very well, and it cam also let the students better understand the content of folk dance by this role-switch. The second is there must be a multi-dimensional evaluation system, for example, the dancing performance activity, dancing contest and classroom performance can account for a very big share in the teaching evaluation system, while the improvisation dancing and self-created dancing can also be a very good way to express the college students`creativity. The third is all-dimensional evaluation methods. The final evaluation of folk dance major in higher institution include not only the final examination, it can also extends to the folk dance gala or performance. By applying the measures mentioned above, it can not only enrich the college students stage performance experience, but also realize the goal of quantitative evaluation. 


\section{Conclusion}

Generally speaking,for the dancing teachers in higher institution, when they conduct the folk dance teaching, simply teaching the dancing skills is not enough, the more important thing is to let the students understand the extremely rich culture content in the folk dance by the teaching innovation. Only by doing so, the folk dance can be showed in front of the audience more truly, thus the higher institution`s students can realize the unique charm and style of the folk dance, and learn this dancing form with a serious attitude.

\section{References}

[1] Chen Hong On Folk Dance Teaching of Music Major in Normal University [J] Hunan social science.2012(1).

[2] Duo Ke On the Current Situation of the Chinese Higher Institution Folk Dance Teaching Reform[J] Big Stage, 2012(12).

[3] Huang Si Analysis and Thinking of Modern China`s Folk Dance Education Mold [J] Beijing Dance Academy Journal, 2013 (1).

[4] Li Nina Local Higher Institution Dance Performance Major <Folk Dance> course teaching reform plan[J] Gehai, 2013(2)

[5] Ma Wenjun Thinking on the Current Situation of Chinese Folk Dance Teaching[J] Jiamusi Education Academy Journal,2014 (1). 